\title{
PP17
}

\section{DIFFERENCES OF LIGHT ENVIRONMENT EVALUATION BETWEEN ELDERLY AND YOUNG PEOPLE}

\author{
Noriko Umemiya et al.
}

DOI 10.25039/x46.2019.PP17

from

CIE x046:2019

\author{
Proceedings \\ of the \\ 29th CIE SESSION \\ Washington D.C., USA, June 14 - 22, 2019 \\ (DOI 10.25039/×46.2019)
}

The paper has been presented at the 29th CIE Session, Washington D.C., USA, June 14-22, 2019. It has not been peer-reviewed by CIE.

(c) CIE 2019

All rights reserved. Unless otherwise specified, no part of this publication may be reproduced or utilized in any form or by any means, electronic or mechanical, including photocopying and microfilm, without permission in writing from CIE Central Bureau at the address below. Any mention of organizations or products does not imply endorsement by the CIE.

This paper is made available open access for individual use. However, in all other cases all rights are reserved unless explicit permission is sought from and given by the CIE.

CIE Central Bureau

Babenbergerstrasse 9

A-1010 Vienna

Austria

Tel.: +4317143187

e-mail: ciecb@cie.co.at

www.cie.co.at 


\title{
DIFFERENCES OF LIGHT ENVIRONMENT EVALUATION BETWEEN ELDERLY AND YOUNG PEOPLE
}

\author{
Umemiya, N. ${ }^{1}$, Qiao, W. ${ }^{1}$ \\ ${ }^{1}$ Osaka City University, Osaka, JAPAN \\ umemiyanor@osaka-cu.ac.jp
}

DOI 10.25039/x46.2019.PP17

\begin{abstract}
Light and Dark conditions were evaluated by elderly people and young people in terms of brightness, glare, comfort and preference using experiments with Dark-to-Light and Light-toDark sequences. Results indicated the following: 1) Elderly people were less sensitive in terms of brightness to the difference of illuminance change order. 2) Elderly people were less sensitive in terms of glare to the difference of illuminance and to the difference of illuminance change order. 3) The Dark condition was evaluated as less comfortable and less preferred than the Light condition in Light-to-Dark experiments for elderly people, although no difference was found for young people between the Dark and the Light conditions in Light-toDark experiments. 4) The Light condition in Dark-to-Light experiments had weaker glare by elderly people than by young people. The Dark condition in Light-to-Dark experiments was evaluated as more comfortable and more preferred by young people than by elderly people.
\end{abstract}

Keywords: Elderly people, Illuminance change, Light environment evaluation

\section{Objective}

Differences of light environment evaluation between elderly and young people have been variously reported from earlier studies, which revealed that elderly people are less sensitive to glare in some conditions. Nevertheless, some researchers have clarified that the sense of glare strengthens with age. Bennett (1977) demonstrated that glare sensation becomes stronger according to age with an equation showing a relation between Border Comfort and Discomfort luminance and age. Takeichi et al. (1995) reported smaller effects of background on elderly people light evaluation. They described the background glare as more uncomfortable. Yamamoto et al. (1996) noted that elderly people felt less glare for a small light source solid angle against a dark luminance background. Mochizuki et al. (2000) clarified that elderly people reported less glare irrespective of the size and luminance of a light source than younger people did.

This study compared light evaluation of brightness, glare, comfort, and preference of elderly and young people in Light and Dark conditions, using both Light-to-Dark and Dark-to-Light experimental sequences. Sequence order effects were also investigated.

\section{Methods}

These experiments assessed 21 elderly people and 106 high school students. Elderly people were 66-88 years old (average $75.0 \mathrm{yr}$; standard deviation $6.7 \mathrm{yr}$ ). Of the elderly people, $43 \%$ were men. Of the high school students, $61 \%$ were male. Second-year students were $44 \%$ and most frequent.

The experiment room and experimental procedure are shown in Figure 1. Four fluorescent lamp instruments and four LED lamp instruments were set on the room's ceiling. Electric power for the lighting was set to $25 \%$ and $100 \%$. The horizontal illuminance on the desk was 600 lux in the Dark condition and 3300 lux in the Light condition.

A maximum of six persons sat around the desk in the experiment room. They evaluated the light environment $10 \mathrm{~min}$ after entrance and evaluated it again $5 \mathrm{~min}$ after the illumination condition changed. Two sequences of experiments were used: Light-to-Dark and Dark-to-Light. The participants evaluated the light environment in terms of brightness, brightness for writing, 

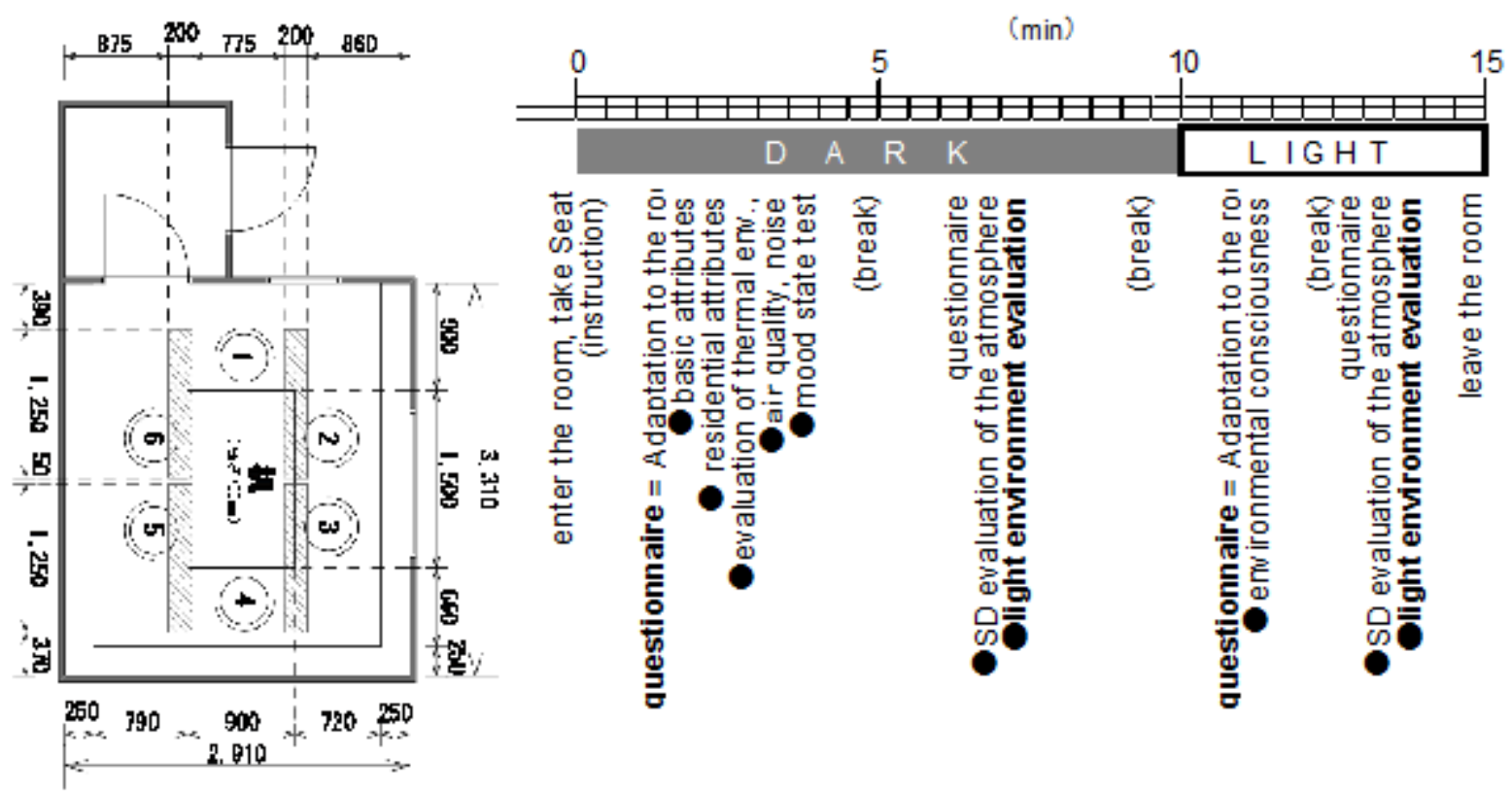

Figure 1 - Experimental room and experimental procedure

uniformity, glare, light color, flickering, lighting comfort, lighting preference, and work performance.

\section{Results and discussion}

\subsection{Differences in light and dark condition evaluations}

Differences in light and dark condition evaluations are shown for Light-to-Dark of young people, Dark-to-Light of young people, Light-to-Dark of elderly people, and Dark-to-Light of elderly people in Figure 2. Vertical axes show mean evaluation values. Two lines in each figure respectively stand for Light and Dark conditions. Solid lines denote the Light-to-Dark sequence. Dotted lines show the Dark-to-Light sequence. White markers represent the Light condition; black markers represent the Dark condition. Circles denote elderly people. Triangles denote young people. Figures in parentheses after evaluation items show $p(\%)$ values for the test of hypothesis related to the mean between Light and Dark. Herein, (-) denotes no significance. Arrows before evaluation items indicate the direction of the evaluation.

Differences of brightness evaluations between Light and Dark conditions were similar for elderly and young people. The $p$ values for both elderly and young people were less than $0.01 \%$ for both Light-to-Dark and Dark-to-Light sequences.

Differences of glare evaluation between Light and Dark conditions were greater for young people $(p<0.01 \%)$ than for elderly people $(p=0.1 \%)$ for both Light-to-Dark and Dark-to-Light sequences.

From the Light-to-Dark sequence experiments, no difference was found in comfort or preference for young people between Light and Dark conditions. However, results show that the Light condition was more comfortable $(p=5 \%)$ and preferred $(p=5 \%)$ than the Dark condition for elderly people.

In Dark-to-Light sequence experiments, the Dark condition was more comfortable $(p=1 \%)$ and preferred $(p=1 \%)$ than the Light condition for young people. However, the Light condition was more comfortable $(p=1 \%)$ and preferred $(p=15 \%)$ than the Dark condition for elderly people. 

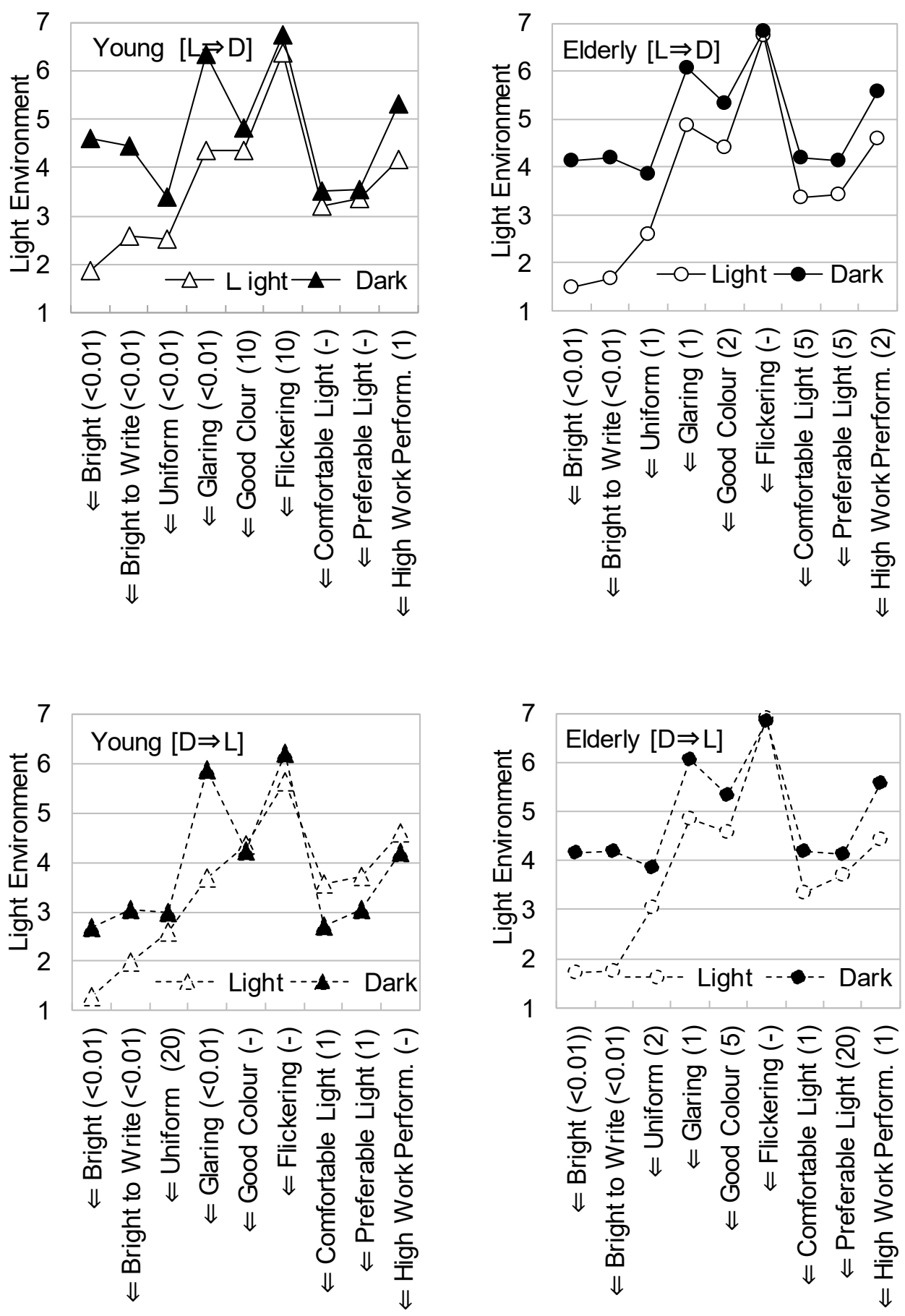

Figure 2 - Differences in light and dark condition evaluations.

\subsection{Differences in evaluation between Dark-to-Light and Light-to-Dark sequences}

Differences in evaluation between Dark-to-Light and Light-to-Dark sequences are shown for the Light condition, respectively, for elderly and young people in Figure 3.

The Light condition of Dark-to-Light sequence experiments was brighter than the Light condition of Light-to-Dark sequence experiments for young people $(p<0.01 \%)$. However, no difference was found between brightness evaluation of the Light condition of Dark-to-Light and Light-to-Dark sequence experiments for elderly people. 
The Light condition of Dark-to-Light sequence experiments had stronger glare than the Light condition of Light-to-Dark sequence experiments for young people $(p=5 \%)$. No difference was found between glare evaluation of the Light condition of Dark-to-Light and Light-to-Dark sequence experiments for elderly people.
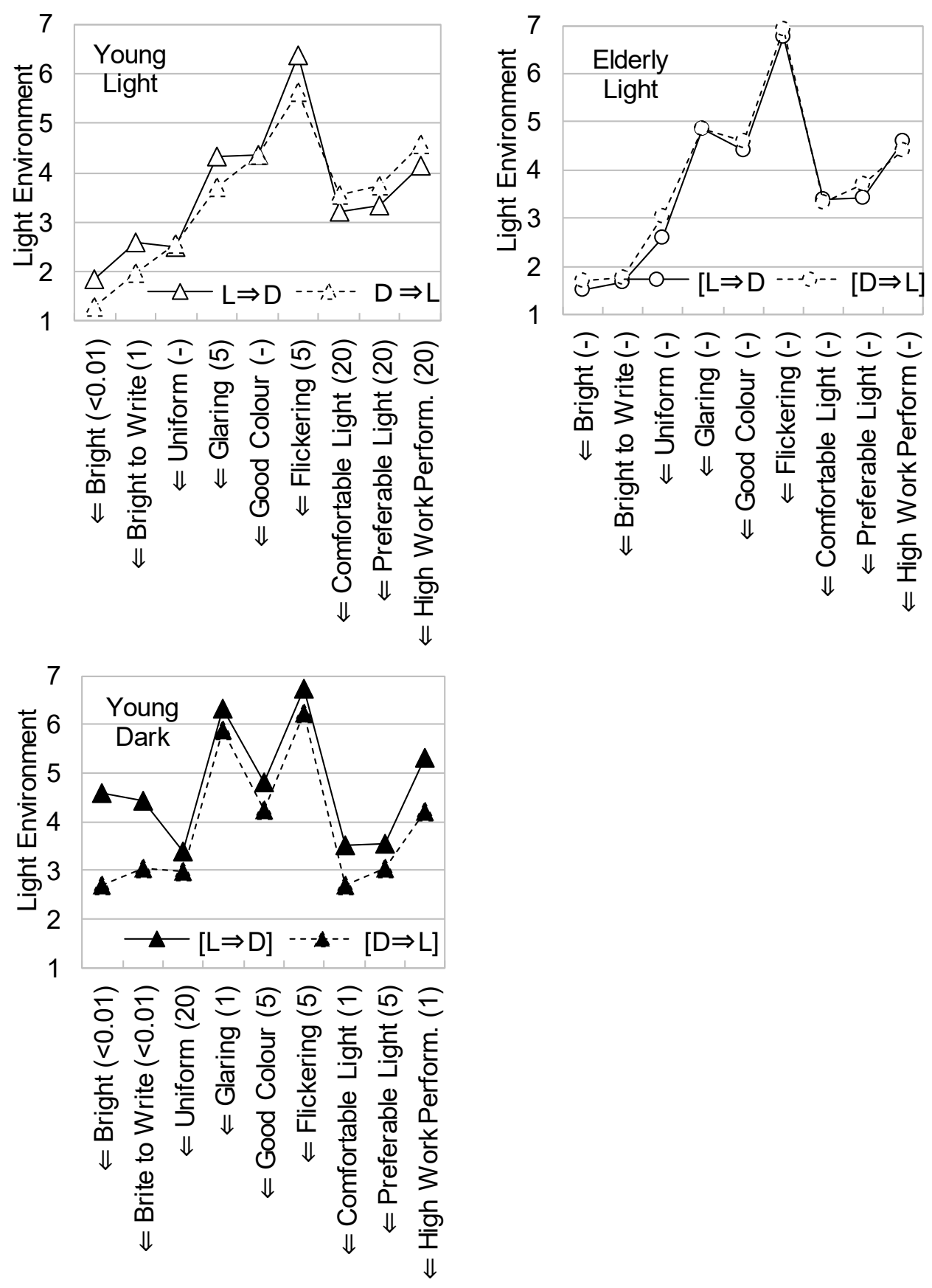

Figure 3 - Differences in evaluations between Dark-to-Light and Light-to-Dark sequences.

The Light condition in Light-to-Dark sequence experiments was more comfortable and more preferred than the Light condition in Dark-to-Light sequence experiments for young people $(p=20 \%$ and $15 \%$, respectively). No difference was found in comfort and preference evaluations of Light condition of Dark-to-Light and Light-to-Dark sequence experiments for elderly people. No difference was found either in all other evaluation items of Light condition of Dark-to-Light and Light-to-Dark sequence experiments for elderly people. Elderly people were less sensitive to differences between the Light condition of Light-to-Dark and Light condition of the Dark-to-Light sequence. 

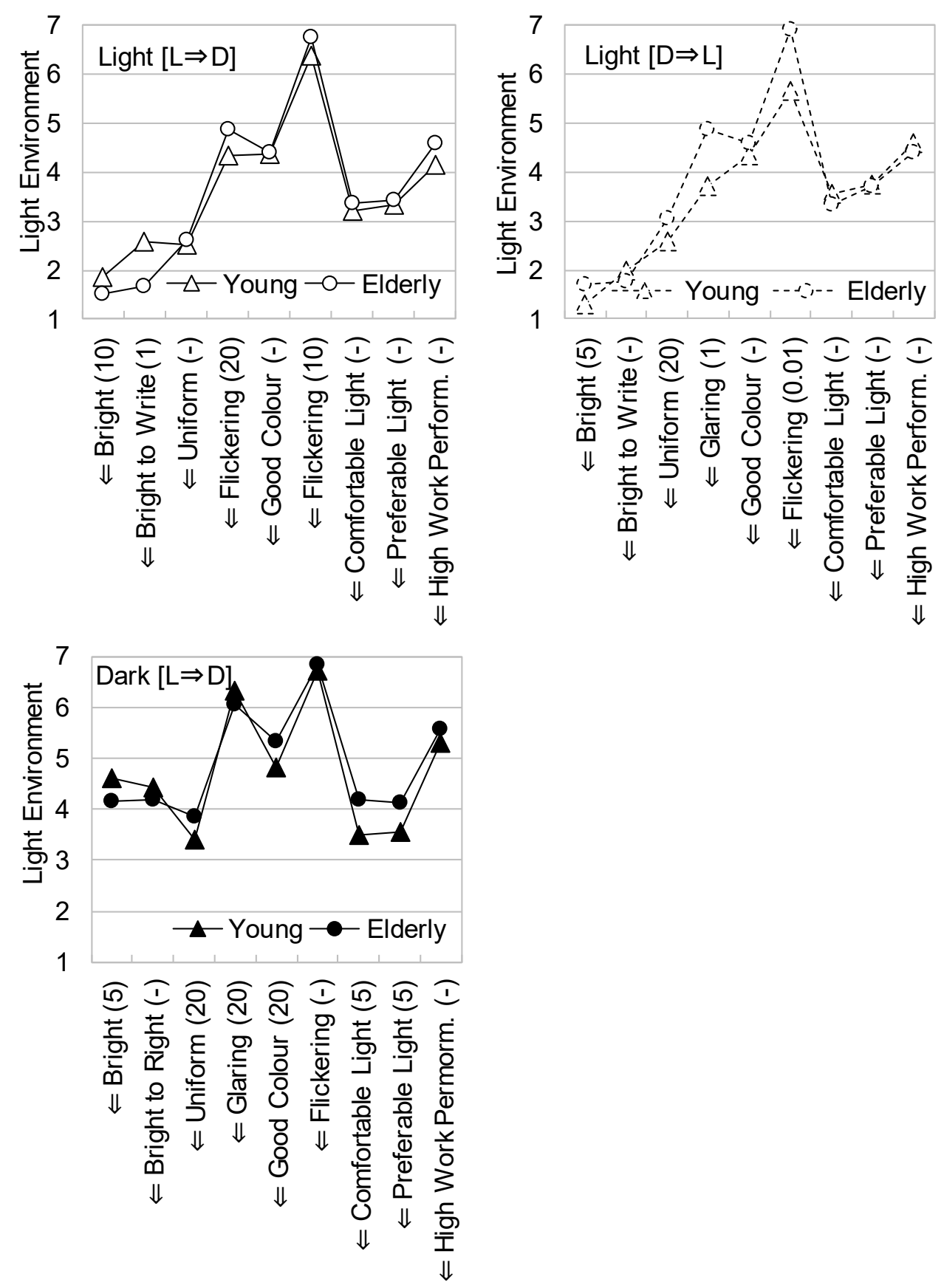

Figure 4 - Differences in evaluations by elderly and young people.

\subsection{Differences in evaluations by elderly and young people}

Differences in evaluations made by elderly and young people are shown in Figure 4.

The Light condition of Dark-to-Light sequence experiments was brighter for young people than for elderly people $(p=5 \%)$. The Light condition of Light-to-Dark sequence experiments was brighter for elderly people than for young people $(p=10 \%)$. The Dark condition of Light-to-Dark sequence experiments was darker for young people than for elderly people $(p=5 \%)$.

The Light condition of Dark-to-Light sequence experiments had weaker glare for elderly people than for young people $(p=1 \%)$. Differences between elderly and young people in glare sensation were smaller for the Light condition of Light-to-Dark sequence experiments and for the Light condition of Dark-to-Light sequence experiments ( $p=20 \%$ for both). 
No difference was found between elderly and young people in comfort evaluation of the Light condition in both Light-to-Dark sequence and Dark-to-Light sequence experiments. The Dark condition in Light-to-Dark sequence experiments was more comfortable and more preferred by young people than by elderly people ( $p=5 \%$ for each).

\section{Conclusions}

Light and Dark conditions were evaluated by 21 elderly people and 106 young people in terms of brightness, glare, comfort, and preference using experiments conducted with Dark-to-Light and Light-to-Dark sequences. Light environment evaluations by elderly and young people were compared. The following results were obtained.

1) Differences in brightness evaluation between Light and Dark conditions were the same for elderly and young people for both Dark-to-Light and Light-to-Dark sequence experiments. Young people evaluated the Light condition as brighter in the Dark-to-Light sequence experiment than the Light condition in the Light-to-Dark sequence experiment, although no difference in brightness was found between the two sequences by elderly people. Elderly people were less sensitive in brightness sensations to differences of the illuminance change order.

2) The difference in glare evaluation between Light and Dark conditions was smaller for elderly people than for young people, irrespective of the sequence of Dark-to-Light or Lightto-Dark. The Light condition in the Dark-to-Light sequence experiment had stronger glare than the Light condition in the Light-to-Dark sequence experiment for young people, although elderly people found no difference in glare between the two sequences. Elderly people were less sensitive to glare sensation than to the difference of illuminance and to the difference of the illuminance change order.

3) The Dark condition was evaluated as less comfortable and less preferred than the Light condition in Light-to-Dark experiments for elderly people, although no difference was found for young people between the Dark and the Light conditions in Light-to-Dark experiments. Elderly people were more sensitive to lighting comfort and preference to the Dark condition in the sequence of Light-to-Dark experiments.

4) The Light condition in Dark-to-Light experiments had weaker glare by elderly people than by young people. The Dark condition in Light-to-Dark experiments was evaluated as more comfortable and more preferred by young people than by elderly people.

\section{References}

BENNETT, C.A. 1977. The Demographic Variables of Discomfort Glare, Lighting Design and Application, 7, 22-24.

MOCHIZUKI, E. et al. 2000. Experimental Study on Discomfort Glare from Large Light Source Judged by Young and Elder people, Journal of Planning and Environmental Engineering of Architectural Institute of Japan, 528, 17-22. (DOI: https://doi.org/10.3130/aija.65.17_1)

UMEMIYA, N. et al. 2013. Mood States and Light Environment Evaluation, Proceedings of CIE Centenary Conference, 1180-1185.

UMEMIYA, N. et al. 2017. Light Evaluation in High and Low mood states, Proceedings of the Midterm Conference of CIE, 687-693.

TAKEICHI, K. et al. 1995. Discomfort Glare of the Aged, Proceedings of Annual Meeting of Japan Ergonomics Society, 36, 340-341. (DOI: https://doi.org/10.5100/jje.31.Supplement -340)

YAMAMOTO, G., et al. 1996. Study on Discomfort Glare Judged by Elderly People Considering of Position of Light Source, Summaries of Technical Papers of Annual Meeting of Architecture Institute of Japan, D1, 307-308.

\section{Acknowledgement}

This study was funded by a JSPS Grant-in-Aid for Scientific Research (C) 17 K06676. 